\title{
Modelo experimental de enfisema pulmonar em ratos induzido por papaína*
}

\begin{abstract}
Laerte Brasiliense Fusco ${ }^{1}$, Paulo M. Pêgo-Fernandes², Alexandre Martins Xavier ${ }^{3}$, Rogério Pazetti 4 , Dolores Helena Rodriguez Ferreira Rivero ${ }^{5}$, Vera luiza Capelozzl ${ }^{2}$, Fabio Biscegli J ATene ${ }^{2}$
\end{abstract}

Objetivo: Com a finalidade de estabelecer uma linha de pesquisa em cirurgia redutora de volume pulmonar, foi proposta a reprodução de um modelo experimental de enfisema em ratos através da instilação intratraqueal de papaína. Métodos: Foi feita a instilação orotraqueal de papaína $(20 \mathrm{mg} / \mathrm{kg})$ dissolvida em 3,5ml/kg de solução fisiológica a 0,9\%. Após 40 dias da instilação, os animais foram submetidos a mecânica ventilatória, com medidas de elastância e resistência do sistema respiratório, e sacrificados com retirada dos pulmões. 0 tecido pulmonar dos animais foi analisado qualitativamente com coloração de hematoxilina-eosina e submetido à análise morfométrica com medida do diâmetro

alveolar médio. 0 tecido pulmonar foi também submetido à coloração de resorcina-fucsina, para identificação de fibras elásticas, que foram quantificadas em septos alveolares através de análise digital de imagem. Resultados: A análise histológica dos pulmões dos animais submetidos à instilação de papaína mostrou um enfisema pan-acinar, com rotura de septos alveolares e hiperdistensão alveolar. A análise morfométrica revelou médias superiores de diâmetro alveolar médio nos pulmões dos animais submetidos à papaína $(149,08 \mu \mathrm{m}$ e $100,56 \mu \mathrm{m})$, em comparação com o grupo de solução fisiológica

$(64,08 \mu \mathrm{m}$ e $75,90 \mu \mathrm{m})$. A quantificação de fibras elásticas de septos alveolares de animais tratados

com papaína foi $70 \%$ menor do que a de animais submetidos à solução fisiológica. A mecânica

ventilatória não mostrou diferença na resistência do sistema respiratório de animais submetidos à papaína ou à solução fisiológica. Já no caso da elastância do sistema respiratório, esta foi menor nos animais do grupo com papaína, em comparação com o grupo com solução fisiológica, demonstrando comportamento funcional do grupo com papaína compatível com enfisema pulmonar, apresentando diminuição da capacidade de recolhimento elástico do tecido pulmonar. Conclusão: Foi possível reproduzir um modelo experimental de enfisema pulmonar pan-acinar em ratos, através da instilação de papaína pela árvore respiratória, com comprovação funcional

e morfológica. (J Pneumol 2002;28(1):1-7)

\section{Papain-induced experimental pulmonary emphysema model in rats}

Objective: The reproduction of an experimental emphysema model in rats by intratracheal

instillation of papain was proposed for the evaluation of lung volume reduction surgeries.

Method: The study used orotracheal instillation of papain $(20 \mathrm{mg} / \mathrm{kg})$ dissolved in $0.9 \%$ saline solution. Forty days after instillation, animals underwent mechanical ventilation. Elastance and resistance of the respiratory system were measured, and the rats were sacrificed by having their lungs removed. The pulmonary tissue of the animals was qualitatively analyzed with hematoxylineosin staining and submitted to morphometric analysis for the measurement of the mean alveolar

diameter. The pulmonary tissue was also subjected to resorcin-fuchsin staining for the

identification of elastic fibers, which were quantified in alveolar septa by digital imaging.

Results: In the animals instilled with papain, the histological analysis of the lungs showed pan-

\footnotetext{
* Trabalho realizado na Faculdade de Medicina da Universidade de São Paulo.

1. Doutor em Medicina.

2. Professor Livre-Docente.

3. Doutorando.

4. Mestrando.

5. Mestre em Fisiopatologia.
}

Endereço para correspondência - Paulo M. Pêgo-Fernandes, Instituto do Coração - HC-FMUSP, Av. Dr. Enéas de Carvalho Aguiar, 44, 2은 andar - 05403-000 - São Paulo, SP. Tel./Fax: (11) 3069-5248; email: paulopego@ incor.usp.br

Recebido para publicação em 30/5/01. Aprovado, após revisão, em 2/10/01. 
acinar emphysema, with rupture of alveolar septa and hyperdistention. Morphometric analysis showed higher mean values for mean alveolar diameter in the lungs of the animals submitted to papain (149.08 $\mu \mathrm{m}$ and $100.56 \mu \mathrm{m})$ as compared to the group receiving saline solution $(64.08 \mu \mathrm{m}$ and $75.90 \mu \mathrm{m})$. The quantification of elastic fibers of alveolar septa of papain-treated animals was $70 \%$ lower than in the animals receiving saline solution. Mechanic ventilation did not show differences in respiratory system resistance of animals receiving papain or saline solution.

Respiratory system elastance was lower in the group receiving papain than in the group receiving saline solution, showing a functional status compatible with pulmonary emphysema, with decreased elasticity of the pulmonary tissue. Conclusion: The reproduction of an experimental model of pan-acinar pulmonary emphysema in rats was achieved by papain instillation through the respiratory tree with functional and morphologic evidences.

Descritores - Enfisema pulmonar. Modelo experimental. Papaína. Ratos. Instilação de medicamentos.

Key words - Pulmonary emphysema. Experimental model. Papain. Rats. Drug instillations.

\section{INTRODUÇÃO}

Diversos tipos de enfisema podem ser definidos, de acordo com o padrão de acometimento da anatomia dos ácinos pulmonares, indicando a etiologia e o comportamento fisiopatológico da apresentação da doença.

0 enfisema pan-acinar apresenta o ácino pulmonar comprometido por um alargamento difuso, habitualmente estendendo-se desde a região hilar até a periferia dos pulmões. Esse enfisema é encontrado nos pacientes portadores de deficiência de alfa-1 antitripsina e é o padrão de enfisema também verificado na reprodução experimental com o uso de enzimas proteolíticas, como papaína e elastase, sendo diretamente relacionado à dose utilizada(1).

Foi observado que pacientes tabagistas podem apresentar os dois tipos de enfisema - centrolobular e panacinar - com graus variáveis de acometimento em um mesmo pulmão(2).

A destruição alveolar acarreta alterações histológicas que podem ser observadas utilizando-se algumas técnicas morfométricas básicas. 0 diâmetro alveolar médio encontra-se aumentado, representando talvez o indicador mais sensível do processo enfisematoso. Os bronquíolos mostram diâmetro interno inferior ao de pulmões normais, mostrando as conseqüências do rompimento da tração elástica radial exercida pelas paredes alveolares sobre as pequenas vias aéreas ${ }^{(3)}$. Esse aspecto ajuda a explicar 0 fechamento precoce das pequenas vias aéreas durante a expiração nos pacientes enfisematosos, com conseqüente retenção de ar ao final desta. Outra medida morfométrica, a superfície alveolar, pode estar reduzida no enfisema, fornecendo o substrato anatômico para o prejuízo de difusão de gases que os pacientes portadores dessa doença podem apresentar ${ }^{(3)}$. Está estabelecido o conceito de que o enfisema apresenta, como característica de mecâ-
Siglas e abreviaturas utilizadas neste trabalho

Esr - Elastância do sistema respiratório

HE - Hematoxilina-eosina

$\mathrm{L}_{\mathrm{i}}$ - Número de interceptos de estruturas alveolares com as retas do retículo

$\mathrm{L}_{\mathrm{m}}$ - Diâmetro alveolar médio

$\mathrm{L}_{\text {tot }}$ - Comprimento total das retas do campo microscópico

Ptr - Pressão traqueal

Rsr - Resistência do sistema respiratório

$\dot{V}$ - Fluxo

$\mathrm{V}$ - Volume

nica ventilatória, diminuição da pressão de recolhimento elástico(4).

Os modelos experimentais de enfisema pulmonar utilizando enzimas proteolíticas, como papaína ou elastase instiladas ou nebulizadas na via respiratória de animais, baseiam-se na teoria de desequilíbrio da produção de substâncias agressoras e protetoras no ácino pulmonar ${ }^{(5)}$. G ross et al. ${ }^{(6)}$, em 1964, foram os primeiros a conseguir reproduzir o enfisema experimental em ratos, com instilação intratraqueal de papaína, enzima proteolítica extraída da fruta e seiva da árvore da papaia (Carica papaya). Esses modelos experimentais resultam em alterações morfo-histológicas e fisiológicas dos pulmões equivalentes às alterações encontradas no enfisema em seres humanos(7).

Takaro e White(8), em 1972, com instilação de solução de papaína em cães, e Haddad et al.(9), em 1979, com nebulização de solução de papaína também em cães, conseguiram produzir enfisema pulmonar, obtendo alterações da mecânica ventilatória, como aumento da capacidade residual funcional, do volume total pulmonar e da complacência pulmonar, demonstrando diminuição da pressão de recolhimento elástico desses pulmões, reproduzindo, assim, alterações funcionais do enfisema pulmonar em humanos.

Os objetivos do presente estudo foram definidos como sendo de reprodução de um método de obtenção de enfisema pulmonar em ratos através de instilação intratraqueal de papaína, associado ao estudo da mecânica ventilatória do sistema respiratório, para o desenvolvimento 
de projetos no campo da cirurgia redutora de volume pulmonar; técnica bastante difundida no tratamento de pacientes com enfisema pulmonar avançado.

\section{MATERIAL E MÉTODOS}

\section{Grupos experimentais}

Foram utilizados 25 ratos machos, não-SPF (não-specific pathogen free), raça Wistar, com peso de $292,24 \mathrm{~g} \pm$ $35,76 \mathrm{~g}$, provenientes do Biotério da Faculdade de Medicina da Universidade de São Paulo. Durante os experimentos, os animais receberam dieta balanceada e água ad libitum.

Este trabalho foi desenvolvido nos Laboratórios de Investigação Médica de Cirurgia Torácica (LIM-61), de Poluição Atmosférica (LIM-05) e de Terapêutica Experimental (LIM-20) da Faculdade de Medicina da Universidade de São Paulo.

Os animais foram divididos em três grupos experimentais:

Grupo A - dez animais expostos à instilação traqueal de solução de papaína e submetidos à ventilação mecânica.

Grupo B - dez animais expostos à instilação traqueal de solução fisiológica isotônica a 0,9\% e submetidos à ventilação mecânica.

Grupo C - cinco animais expostos à instilação traqueal de solução de papaína sem ser submetidos à ventilação mecânica.

\section{Anestesia}

Todos os animais foram submetidos à sedação com éter etílico (Rioquímica Ltda.). Foram submetidos à anestesia geral com enflurano a $2 \%$ (E trane $\left.{ }^{\circledR}\right)$, utilizando-se um nebulizador de gases Enflovapor modelo $1223 \mathrm{~K}$. Takao$\mathrm{ka}$ com volume corrente de $10 \mathrm{ml} / \mathrm{kg}$, com freqüência respiratória de 80 ciclos por minuto.

\section{Ventilação mecânica}

A pós à intubação orotraqueal, os animais dos grupos A e $B$ foram submetidos à ventilação mecânica (H arvardRodent Ventilator model 683) com volume corrente de $10 \mathrm{ml} / \mathrm{kg}$, com freqüência respiratória de 80 ciclos por minuto.

0 objetivo do grupo $C$, não-submetido à ventilação mecânica, foi o de controlarmos os possíveis efeitos dessa ventilação no parênquima pulmonar, sabidamente causador de hiperdistensão e alterações deste parênquima.

\section{Indução de enfisema por papaína}

Os animais dos grupos $A$ e $C$ foram submetidos à instilação de $3,5 \mathrm{ml} / \mathrm{kg}$ de solução de papaína em solução fisiológica isotônica a 0,9\% (Crystallized, lyophilizide pow- der/10-20 units per mg protein Sigma $\left.{ }^{\circledR}\right)$, correspondente a $20 \mathrm{mg} / \mathrm{kg}$ de rato (cerca de $6 \mathrm{mg}$ de papaína por animal), através de instilação por sonda orotraqueal, em infusão lenta, por cerca de dois minutos.

Os animais do grupo B foram submetidos à instilação de $3,5 \mathrm{ml} / \mathrm{kg}$ de solução fisiológica isotônica a $0,9 \%$ por sonda orotraqueal, também em infusão lenta, por cerca de dois minutos.

\section{Mecânica ventilatória}

Após 50 dias da instilação intratraqueal da solução fisiológica ou da solução de papaína, os animais dos grupos A e B foram anestesiados com Thionembutal ${ }^{\circledR}$ (tiopental sódico - 0,5g), com uma dose de $30 \mathrm{mg} / \mathrm{kg}$ e submetidos a acesso da via aérea. Foram, então, ventilados em ventilador para pequenos animais (H arvard 683, Harvard Apparatus Co., South Natik, MA), na freqüência de 80 ciclos por minuto, com volume corrente de $10 \mathrm{ml} /$ $\mathrm{kg}$. A cânula foi conectada a um pneumotacógrafo A. Fleisch 0000 (O.E.M., Virginia, EUA) e este a um transdutor de pressão diferencial (Validyne DP 45-16-2114, Validyne Corp. (Northridge, CA), para medir o fluxo respiratório. A pressão traqueal (Ptr) foi medida com um transdutor de pressão Validyne DP 45-16-2114 ligado a uma peça metálica em formato de " $\mathrm{T}$ ", que foi colocada em série com a cânula traqueal e o pneumotacógrafo. Os sinais de fluxo e da pressão traqueal foram registrados num polígrafo Gould RS 3400 e, através de um conversor analógico-digital de 12 bites (DT2801A, Data Translation), armazenados num microcomputador a uma freqüência de $200 \mathrm{~Hz}$. Cada dado foi obtido com a média de 13 ciclos respiratórios. Os sinais de fluxo foram integrados, obtendo-se, assim, as variações de volume pulmonar (V).

Durante todo o processo de captação dos sinais de fluxo e pressão, estes foram visibilizados, a fim de detectar eventuais vazamentos de ar do sistema (alterações bruscas de pressão) ou presença de secreção nas vias aéreas (presença de ruídos nos sinais).

A resistência do sistema respiratório (Rsr) e a elastância do sistema respiratório (Esr) foram obtidas a partir da equação do movimento adaptada para o sistema respiratório:

$$
\mathrm{Ptr}=\mathrm{Esr} \cdot \mathrm{V}(\mathrm{t})+\mathrm{Rsr} \cdot \dot{\mathrm{V}}(\mathrm{t})
$$

em que ( $\mathrm{t}$ ) é o tempo, $\mathrm{V}$ é o volume, $\dot{V}$ o fluxo.

Após as medidas de mecânica ventilatória, os animais dos grupos A e B foram sacrificados por meio de abertura da cavidade abdominal e secção total da aorta abdominal, com retirada dos blocos de coração e pulmões. Os animais do grupo $C$ também foram sacrificados pelo mesmo método. 


\section{Morfometria e histologia}

Os pulmões dos animais de todos os grupos foram processados conforme a técnica a seguir. Após retirada dos blocos de coração e pulmão, os pulmões direitos foram submetidos à fixação imediata em nitrogênio líquido por dois minutos, colocando-se, em seguida, em solução Carnoy (etanol: clorofórmio: ácido acético, na proporção de 60:30:10), mantendo-se por 24 horas a uma temperatura de 20 graus Celsius negativos. Após esse período, foram deixados, por uma hora, em etanol a $70 \%$, progressivamente até etanol absoluto. Após 24 horas, a uma temperatura de 4 graus Celsius negativos, o material foi colocado em formaldeído a $10 \%$ para, então, serem realizados os cortes de parênquima pulmonar com espessura de $5 \mu \mathrm{m}$ e corados com hematoxilina e eosina (HE), para análise qualitativa e quantitativa da ação da papaína.

A quantificação do enfisema pulmonar foi verificada pela presença de destruição alveolar determinada pela medida do diâmetro alveolar médio em micrômetros $\left(\mathrm{L}_{\mathrm{m}}\right)$. Resumidamente, essa técnica consiste na determinação do número de vezes que estruturas do parênquima de troca gasosa intercepta um conjunto de retas coerentes(10).

Dessa forma, no caso de presença de enfisema, o número de interceptos das estruturas alveolares com o sistema de retas será menor, indicando destruição alveolar. 0 diâmetro alveolar médio $L_{m}$ é obtido pela relação:

$$
\mathrm{L}_{\mathrm{m}}=\mathrm{L}_{\text {tot }} / \mathrm{L}_{\mathrm{i}}
$$

em que $L_{\text {tot }}$ é o comprimento total das retas do campo microscópico e $L_{i}$ é o número de interceptos de estruturas alveolares com as retas do retículo. Com objetivo de realizar a morfometria, cinco campos microscópicos ( $\mathrm{Ni}$ kon YS2), com aumento de 100 vezes, escolhidos aleatoriamente, não-coincidentes, foram examinados com a ajuda de uma ocular integradora.

o estudo qualitativo analisou os aspectos histopatológicos do parênquima pulmonar submetido à ação da solução de papaína ou da solução fisiológica.

\section{Quantificação de fibras elásticas}

0 tecido pulmonar foi submetido a análise e quantificação das fibras elásticas presentes nos septos interalveolares, selecionando-se aleatoriamente dez campos, com aumento de 400 vezes, de cinco animais expostos à instilação de solução de papaína e quatro animais à instilação de solução fisiológica. As fibras do sistema elástico que contêm elastina são identificáveis pelo método da resorcina-fucsina de Weigert (Figura 1). A quantificação das fibras elásticas foi feita com a ajuda de um sistema de análise digital, que utilizou um programa específico (Bioscan-Optimas; Bioscan Inc., Edmont, WA).

As imagens foram geradas por microscópio (Zeiss Axioplan; Zeiss, Oberkochen, Alemanha), sendo enviadas,

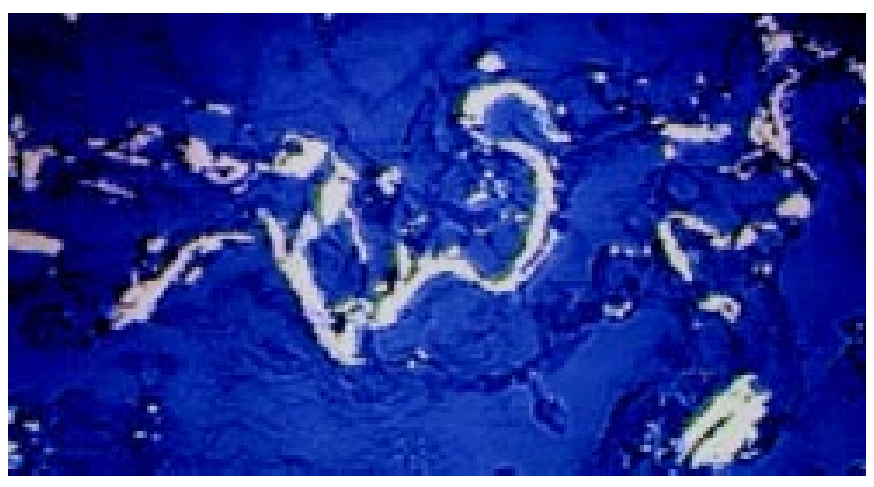

Figura 1 - Análise e quantificação das fibras elásticas presentes nos septos interalveolares identificáveis pelo método da resorcina-fucsina de Weigert

através de um processador digital de imagem (Oculus TCX; Coreco, St. Laurent, PQ, Canadá), a um monitor (Sony Trinitron CCD; Sony, Tóquio, Japão), que alimentava diretamente um computador (Pentium 100M hz). Este programa permite delimitar a área a ser estudada através do estabelecimento prévio de padrões de cores, num espectro que vai do preto a diversos tons de cinza, criandose um padrão de referência a partir do qual o computador reconhece o substrato em estudo e fornece a área ocupada por este. 0 padrão para reconhecimento de fibras elásticas é estabelecido individualmente para cada caso, calibrando-se o contraste a um nível em que as fibras são facilmente reconhecidas. A área ocupada pelas fibras elásticas é determinada por densitometria digita|(11). Conseguimos obter, assim, a percentagem das fibras elásticas em septos alveolares de pulmões submetidos à ação da papaína ou da solução fisiológica a 0,9\%.

\section{Métodos estatísticos}

Inicialmente, todas as variáveis foram analisadas descritivamente. Para as variáveis contínuas, essa análise foi feita através da observação dos valores mínimos e máximos, do cálculo de médias, desvio padrão e medianas. Para as variáveis classificatórias, calcularam-se freqüências absolutas e relativas.

Para testar a hipótese de igualdade entre os grupos, foi utilizado o teste não-paramétrico de Kruskall-Wallis com comparações múltiplas pelo teste de Dunn ${ }^{(12)}$. 0 nível de significância utilizado para os testes foi de $5 \%$.

Para a análise estatística da quantificação de fibras elásticas, foi utilizado o teste não-paramétrico específico para amostras pequenas de Mann-Whitney $(p=0,006)^{(13)}$.

\section{Resultados}

\section{Considerações gerais}

Durante a exposição dos animais à instilação de solução fisiológica ou solução de papaína, estes se apresenta- 
ram mais letárgicos nas primeiras horas devido ao procedimento anestésico. Nossa taxa de mortalidade no grupo A, submetido à instilação de solução de papaína, foi de $20 \%$ (dois animais), enquanto no grupo $B$, submetido à instilação de solução fisiológica a $0,9 \%$, foi de $10 \%$ (um animal). Em alguns animais pudemos identificar como causa direta da morte a própria agressão enzimática provocada pela papaína, pois apresentaram desconforto respiratório acompanhado de hemoptise. Não houve mortalidade no grupo $\mathrm{C}$.

Maiores dimensões dos corações de animais submetidos à papaína em comparação com animais expostos à solução fisiológica foram muito freqüentes nas dissecções dos blocos coração-pulmão.

\section{Mecânica ventilatória}

Encontramos o seguinte resultado para a resistência do sistema respiratório:

- A resistência do sistema respiratório (Rsr) no grupo A (solução de papaína com ventilação mecânica) e a no grupo B (solução fisiológica com ventilação mecânica) não apresentou diferença estatisticamente significante (Figura 2).

- Para a elastância do sistema respiratório, temos que os grupos diferem entre si, utilizando-se o método nãoparamétrico de Kruskall-Wallis $(p=0,001)$.

Realizando-se a comparação múltipla pareada (método de Dunn), encontramos o seguinte:

- A elastância do sistema respiratório (Esr) do grupo A foi estatisticamente menor do que a elastância do grupo B (Figura 3).

\section{Histopatologia e MORFOMETRIA}

\section{Análise quantitativa morfométrica}

Realizando estudos morfométricos com análise do diâmetro alveolar médio $\left(\mathrm{L}_{m}\right)$, obtivemos os seguintes resultados:

- A média do diâmetro alveolar médio do grupo A (papaína com ventilação mecânica) foi de $146,61 \mu \mathrm{m}$

- A média do diâmetro alveolar médio do grupo B (so-

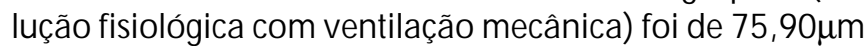

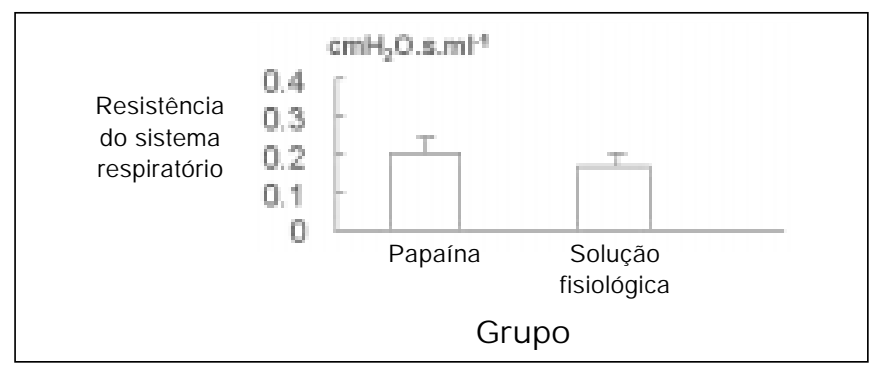

Figura 2 - A resistência do sistema respiratório nos dois grupos não apresentou diferença estatisticamente significante $(p<0,05)$
- A média do diâmetro alveolar médio do grupo C (solução de papaína sem ventilação mecânica) foi de 100,56 $\mu \mathrm{m}$.

Para a análise estatística dos resultados de diâmetro alveolar médio, agrupamos a média do grupo A $(149,17$ $\mu \mathrm{m})$ e, para analisarmos os efeitos da papaína e da ventilação mecânica, agrupamos a média do grupo B $(75,90$ $\mu \mathrm{m})$.

Encontramos diferença estatística significante entre os três grupos $(p<0,0001)$. 0 grupo $C$ (papaína sem ventilação mecânica) não apresentou diferença significativa em comparação com o grupo submetido à papaína com ventilação mecânica. Os grupos papaína com e sem ventilação mecânica apresentam diferença significante comparados com o grupo submetido à solução fisiológica com ventilação mecânica (Figura 4).

Análise qualitativa

A Figura 3 representa o pulmão do grupo C (papaína sem ventilação mecânica).

a) Hematoxilina-eosina

Cortes histológicos obtidos dos pulmões de ratos tratados com papaína demonstraram quadro de enfisema panacinar com histoarquitetura lobular preservada, reconhecendo-se bronquíolo terminal, bronquíolo respiratório e tecido alveolar adjacente (Figura 6). A análise do ácino pulmonar evidenciou rotura dos septos alveolares, com

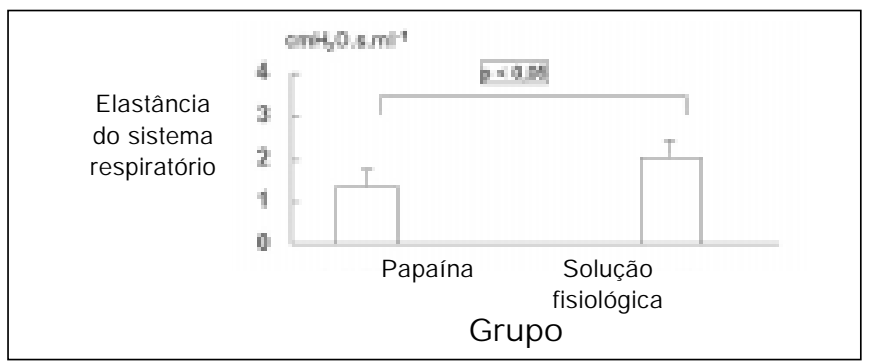

Figura 3 - A elastância do sistema respiratório (Esr) do grupo $A$ (papaína) foi estatisticamente menor do que a do grupo $B$ (solução fisiológica) $(p<0,05)$

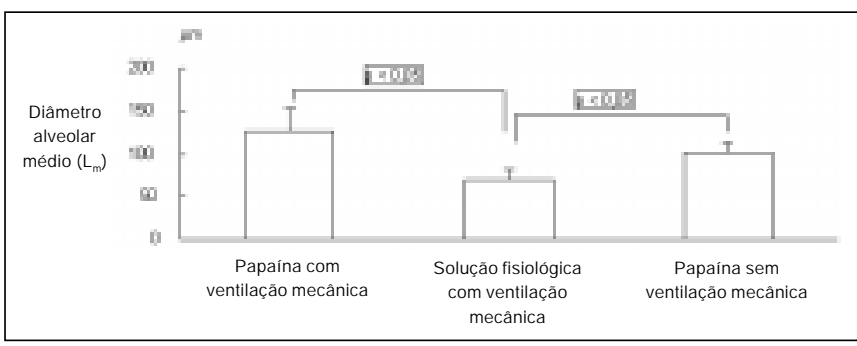

Figura 4 - O diâmetro alveolar médio dos grupos papaína e papaína sem ventilação mecânica apresentou diferença estatística significante em relação ao grupo de solução fisiológica $(p<0,05)$ 


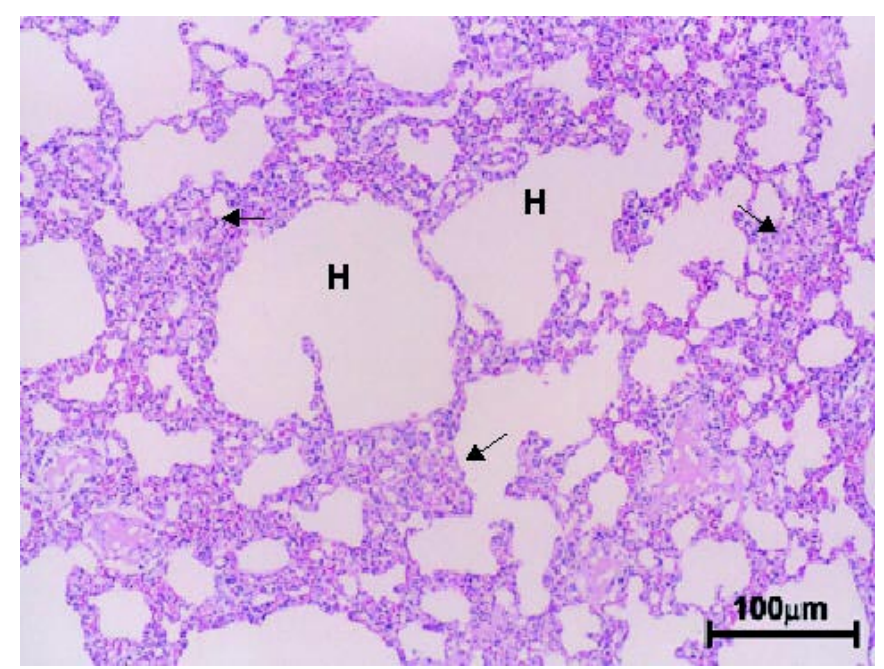

Figura 5 - Pulmão submetido à papaína sem ventilação mecânica com enfisema pan-acinar, hiperdistensão e zonas de microatelectasia (HE 40x)

formação de estruturas "fibrosas" nas extremidades dessa rotura, conhecidas como "baquetas" e características da lesão enfisematosa.

As alterações foram constatadas em mesma intensidade nos grupos submetidos à ação da papaína com e sem ventilação mecânica.

A hiperdistensão alveolar com e sem rotura de septos alveolares determina alterações difusas de ventilação-perfusão evidenciadas por áreas de desacoplamento entre alvéolos e o eixo axial perivascular e pela presença de áreas de microatelectasias. Identificamos processo de espessamento de septos interalveolares com proliferação fibrosa.

b) Resorcina-fucsina

0 estudo do tecido alveolado componente de parte do ácino foi submetido à coloração pela resorcina oxidada, para estudo do citoesqueleto elástico. A Figura 7 demonstra a disposição da histoarquitetura do arcabouço elástico, sob visão panorâmica, onde são evidentes a perda de continuidade da lâmina elástica e o espessamento.

\section{Quantificação de fibras elásticas}

A média da fração de área ocupada pelas fibras elásticas nos pulmões tratados com papaína foi de 1,4\%, enquanto nos animais submetidos à solução fisiológica a $0,9 \%$ foi de $17,08 \%$.

A comparação das médias encontradas nos dois grupos revelou diminuição de $70 \%$ na média da fração de área ocupada pelas fibras elásticas, nos pulmões tratados com papaína.

A análise da diferença na média da fração de área ocupada pelas fibras elásticas, através do teste de MannWhitney, foi estatisticamente significante $(p=0,006)$.

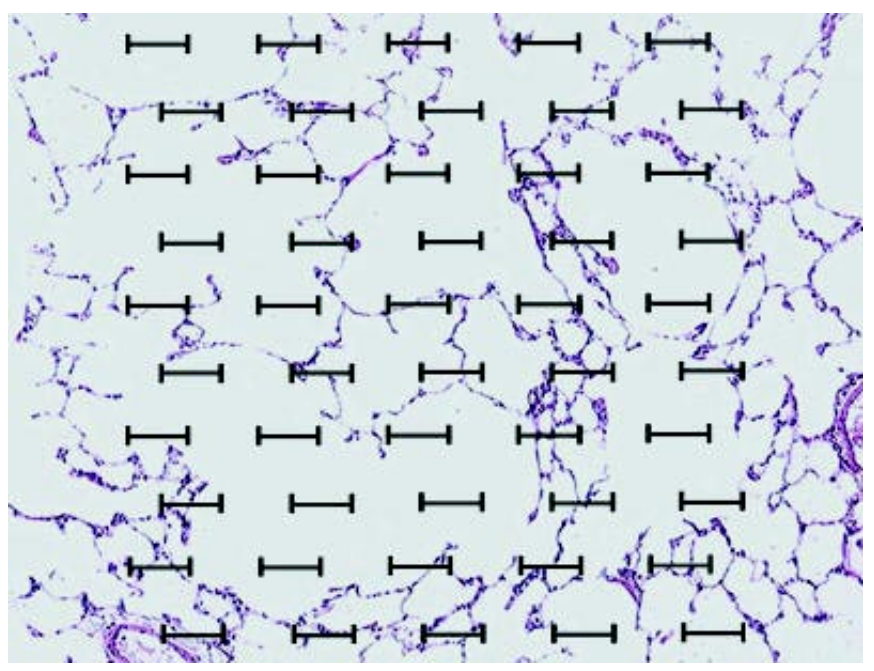

Figura 6 - Corte histológico de pulmão de rato submetido à papaína com retículo para análise morfométrica (HE 100x)

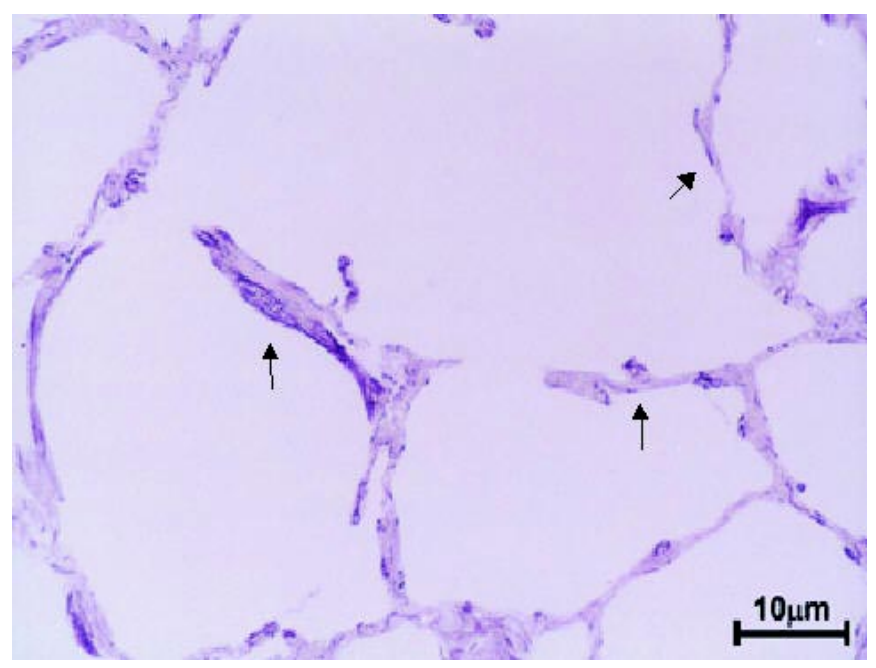

Figura 7 - Pulmão submetido à papaína com enfisema pan-acinar, adensamento de fibras elásticas contrastando com áreas desnudas ao longo dos septos (resorcina-fucsina 400x)

\section{DIsCUSSÃO}

A literatura mostra que os modelos de enfisema pulmonar que utilizam instilação ou nebulização de enzimas proteolíticas através da via respiratória mostraram-se eficazes na reprodução dessa doença(1,7,14). Optamos, assim, pelo método da instilação de papaína via intratraqueal para obtenção de enfisema pulmonar em ratos.

As alterações histopatológicas e morfométricas encontradas em pulmões submetidos à ação da papaína demonstram aumento de espaços alveolares, com ruptura de septos alveolares, satisfazendo critérios morfológicos de reprodução do enfisema pulmonar pan-acinar. 0 diâmetro alveolar médio de ratos sem doenças pulmonares é da 
ordem de $70 \mu m^{(15)}$. Nossos grupos submetidos à instilação de solução fisiológica apresentaram médias de $75,90 \mu \mathrm{m}$ (grupo B), bem compatíveis com dados da literatura. Os animais dos grupos expostos à ação da papaína apresentaram médias de 149,18 $\mu \mathrm{m}$ (grupo A) e 100,56 $\mu \mathrm{m}$ (grupo C).

Em relação às alterações histo patológicas encontradas, surgiram dúvidas sobre um possível efeito da ventilação mecânica. Decidimos criar um grupo-controle para análise dessa variável, o grupo $C$, de animais submetidos à instilação de papaína, mas que não fossem expostos à ventilação mecânica. Esse grupo apresentou alterações compatíveis com enfisema pan-acinar, com média menor do diâmetro alveolar médio em comparação com os animais submetidos à instilação de papaína e à ventilação mecânica (grupo A) e com média maior do diâmetro alveolar médio em comparação com os expostos à instilação de solução fisiológica e à ventilação mecânica (grupo B). Esses resultados evidenciam que a papaína produziu alterações enfisematosas, mas que pode ter havido um efeito adjuvante da ventilação mecânica sobre o parênquima, que sofreu a ação da papaína, produzindo hiperdistensão alveolar e resultando em média maior dos diâmetros alveolares médios. Esse efeito da ventilação mecânica não foi observado no grupo $B$ submetido à instilação de solução fisiológica, uma vez que as médias do diâmetro alveolar médio desse grupo foram compatíveis com os padrões encontrados na literatura para pulmões normais de ratos Wistar, como foi comentado anteriormente.

Podemos especular que foi possível a ventilação mecânica exercer algum efeito sobre o parênquima pulmonar por encontrar um pulmão já comprometido pela ação da papaína, produzindo, assim, maior grau de hiperdistensão alveolar em comparação com o grupo submetido exclusivamente à ação da papaína. É lícito imaginar que a ventilação mecânica tenha contribuído para aumentar as médias do diâmetro alveolar médio do grupo $\mathrm{A}$, mas, como pudemos notar nos resultados apresentados, a análise estatística da média conjunta desses grupos não apresentou diferença em relação à média do grupo submetido a papaína e ventilação mecânica, assegurando, assim, que a papaína foi a responsável pelas alterações morfológicas e funcionais encontradas nesses grupos.

0 enfisema apresenta como principal alteração funcional diminuição na pressão de recolhimento elástico do pulmão, ou seja, há menor elastância do tecido pulmonar ${ }^{(16)}$.

Nos estudos de mecânica ventilatória que realizamos, preocupamo-nos em analisar a resistência e a elastância do sistema respiratório. A elastância do sistema respiratório pareceu-nos o parâmetro adequado para a monitorização da capacidade de recolhimento elástico do pulmão(17). Os ratos expostos à papaína apresentaram diminuição dos valores de elastância, caracterizando um decréscimo da capacidade de recolhimento elástico, compatível com o perfil funcional do enfisema pulmonar humano. A resistência do sistema respiratório, neste modelo utilizando papaína, não sofreu alterações significantes, demonstrando que as alterações de vias aéreas não produziram repercussão funcional. Esses dados reforçaram os achados histológicos e morfológicos de termos reproduzido um modelo para estudo da doença enfisematosa pulmonar e não de um modelo de estudo de doença pulmonar obstrutiva crônica com padrão bronquítico com alteração funcional da resistência das vias aéreas secundária à inflamação e hiper-reatividade brônquica.

Essa investigação experimental confirma que se pode obter enfisema experimental em ratos com a instilação de papaína na árvore respiratória. Mostra também que esse modelo apresenta características morfológicas e fisiopatológicas semelhantes ao humano e que não provoca repercussões na resistência do sistema respiratório.

\section{REFERÊNCIAS}

1. Snider GL, Lucey EC, Stone PJ. Animal models of emphysema. Am Rev Respir Dis 1986;133:149-69.

2. Kim WD, Eidelman DH, Izquierdo J L, Ghezzo H, Saetta MP, Cosio MG. Centrilobular and panlobular emphysema in smokers. Two distinct morphologic and functional entities. Am Rev Respir Dis 1991 144:1385-90.

3. Saetta M, Ghezzo H, Kim WD, King K, Angus GE, Wang NS, et al. Loss of alveolar attachments in smokers. A morphometric correlate of lung function impairment. Am Rev Respir Dis 1985;132:894-900.

4. Macklem PT, Eidelman D. Reexamination of the elastic properties of emphysematous lungs. Respiration 1990;57:187-92.

5. Janoff A. Elastases and emphysema. Current assessment of the protease-antiprotease hypothesis. Am Rev Respir Dis 1985;132:417-33.

6. Gross P, Bajak MA, Tolker E, Kaschak M. Enzymatically produced pulmonary emphysema: a preliminary report. J Occup Med 1964;6: 481-3.

7. Hayes J A, Korthy A, Snider GL. The pathology of elastase-induced panacinar emphysema in hamsters. J Pathol 1975;117:1-14.

8. Takaro T, White SM. Emphysema. Am Rev Respir Dis 1973;108:334-7

9. Haddad AG, Pimmel RL, Scaperoth DD, Bromberg PA. Forced oscillatory respiratory parameters following papain exposure in dogs. J Appl Physiol 1979;46:61-6.

10. Weibel ER. Principles and methods for the morphometric study of the lung and others organs. Lab Invest 1963;12:131-7.

11. Uitto J, Paul J L, Brockley K, Pearce RH, Clark J G. Elastic fibers in human skin: quantitation of elastic fibers by computerized digital image analyses and determination of elastin by radioimmunoassay of desmosine. Lab Invest 1983:49:499-505.

12. Rosner B. Fundamentals of biostatistics. $2^{\text {nd }}$ ed. Boston: PWS Publishers, 1986.

13. Siegel S. Estatistica não-paramétrica. São Paulo: McGraw-Hill do Brasil, 1975

14. Johanson Jr WG, Pierce AK, Reynolds RC. The evolution of papain emphysema in the rat. J Lab Clin Med 1971;78:599-607.

15. Baker HJ, Lindey JR, Weisbroth JH. The laboratory rat - Biology and diseases. New York: Academic Press, 1979.

16. Stead WW, Fry DL, Ebert RV. The elastic properties of the lung in normal men and in patients with chronic pulmonary emphysema. Am Rev Respir Dis 1952:674-9.

17. Zin WA. Assistência ventilatória mecânica. São Paulo: Atheneu, 1995; 3-39. 